Article

\title{
Towards an Inclusive Museum Management Strategy. An Exploratory Study of Consumption Experience in Visitors with Disabilities. The Case of the CosmoCaixa Science Museum
}

\author{
Monica Cerdan Chiscano * and Ana Isabel Jiménez-Zarco (D) \\ Economics and Business Studies, Open University of Catalonia, 08029 Barcelona, Spain; ajimenezz@uoc.edu \\ * Correspondence: mcerdanc@uoc.edu
}

check for updates

Citation: Cerdan Chiscano, M.; Jiménez-Zarco, A.I. Towards an Inclusive Museum Management Strategy. An Exploratory Study of Consumption Experience in Visitors with Disabilities. The Case of the CosmoCaixa Science Museum. Sustainability 2021, 13, 660. https:// doi.org/10.3390/su13020660

Received: 4 December 2020 Accepted: 22 December 2020 Published: 12 January 2021

Publisher's Note: MDPI stays neutral with regard to jurisdictional clai$\mathrm{ms}$ in published maps and institutional affiliations.

Copyright: (C) 2021 by the authors. Licensee MDPI, Basel, Switzerland. This article is an open access article distributed under the terms and conditions of the Creative Commons Attribution (CC BY) license (https:// creativecommons.org/licenses/by/ $4.0 /)$.

\begin{abstract}
In the field of cultural tourism, museums have been pioneers in focusing on visitors with disabilities. They have used inclusive orientation to offer the kind of memorable and satisfying experiences that are so beneficial to a group at constant risk of social exclusion. Their task is made more difficult, however, by visitors' perception of barriers to inclusion, and identification therefore becomes a priority at the strategic level. Based on this idea, the present study analyzes experiences from two tours of the CosmoCaixa Barcelona museum by 32 people with disabilities (PwD). The use of ethnographic techniques and post-experience interviews shows how, despite the legal framework in relation to people with disabilities, hospitality managers find it difficult to put this framework into practice and cater to the needs of this segment of the population. Two factors become particularly clear: the difficulties experienced by museum staff in identifying people with disability, and museum managers' lack of training and knowledge of the wants and needs of people with disabilities. Academic and strategic recommendations for museum managers are provided at the end of the article.
\end{abstract}

Keywords: inclusive management; people with disabilities; customer experience; consumer value

\section{Introduction}

The concept of inclusion has become very important in the context of cultural tourism. Its scope means that inclusive organizations must not only be consumer-focused, but also require a strategic orientation that allows them to manage diversity with equity and justice in a sustainable way [1].

Contemporary customers no longer demand quality alone; increasingly, they also demand social, emotional, and epistemological value [2] obliging organizations to be socially responsible, inclusive, and capable of offering satisfactory experiences [3]. As organizations that house collections of objects for inspection, study, and enjoyment [4] traditionally museums have invested in delivering value by individualizing relations and optimizing the experience irrespective of the customer [5]. However, their modern-day recognition as organizations that also carry out social work [6] has led them to focus on invisible groups such as people with disabilities [7]. At the organizational level, inclusive management improves as consumers are better understood. By identifying consumers' wants and needs and the type of relationship they are seeking, organizations have increased their ability to realize them [8]. However, as [9,10] point out, inclusive museum management requires going one step further, by strengthening the emotional dimension that characterizes this concept and offering the visitor vivid, unique, and memorable experiences [1].

Interestingly [11]'s study shows that the experiences of visitors with and without disabilities are affected by the presence or absence of certain elements and practices in the museum service environment that facilitate total inclusion. However, this task becomes complicated when the museum focuses on visitors with disabilities [12], since their degree 
of disability may mean that they are dependent on other people [13] (who may influence their perceptions, feelings, and experiences [14].

The limited amount of research so far conducted in this area points to the presence of architectural barriers as one element that restricts inclusive management in museums [15]. However, it remains necessary to identify the presence of other types of elements that prevent visitors with disabilities from having unique and memorable experiences, especially from an emotional point of view.

Accordingly, this paper proposes to answer the following questions: (1) What barriers to inclusion are identified by visitors with disabilities? (2) What kind of practices need to be implemented to achieve an inclusive museum management strategy?

The study of two experiences of a visit to the CosmoCaixa museum made by 32 people with disabilities (PwD) demonstrates that, despite the legal framework provided by the Convention of Rights of People with Disabilities [16] the main weakness is inclusive management: staff find it difficult to identify $\mathrm{PwD}$, and museum managers lack the training and knowledge to better understand their wants and needs, preventing them from designing the correct strategies that will enable them to offer $\mathrm{PwD}$ unique and memorable experiences.

The article ends by identifying important academic and strategic implications that illustrate that museums need to listen to visitors with disabilities. This will provide managers with an inclusive management tool for the creation of potential encounters or touchpoints in which they can be more present in the cultural experiences of visitors with disabilities.

\section{Conceptual Background}

\subsection{The Visitor with Disabilities Experience}

The customer-centric approach goes beyond knowing the customer to offering a product adapted to their needs and preferences; today, it is about offering unique and memorable experiences [1].

Organizations have begun to focus on collecting insights into what their customers want, how they expect to be helped, and how to promise and deliver what they really want and need in the best possible way. As a consequence, customer experience has become a key strategic objective for organizations wishing to effectively interact with and build strong relationships with customers [17].

Furthermore [18] define experiences-which lead to value outcomes-as multidimensional, involving sensory, emotional, cognitive, physical, and relational or social perceptions $[19,20]$. Several authors define a memorable experience as "surpassing all expectation, whether in shortfall or excess, and resulting in full satisfaction-or dissatisfaction". This concurs with [21] who affirms that the emotional nature of the experience derives from "entertaining, pleasurable, memorable, and striking encounters".

Consumers' experiences are the result of their entire journey with the brand [20] the dynamic and interactive process consisting of the flow of interactions and encounters that take place between a client and a product or supplier [22] and also with the environment, whether online or physical, in which certain contacts are established [23] with company personnel and other customers $[17,21]$. All of these are customer experience touchpoints, though only some of them are under the company's control.

Interactions can be direct or indirect [24] but experience is strictly personal. [25] show that consumers' experiences occur in their own lives, and the value outcome depends on how they react to the staged encounter, based on their consciousness and state of mind. Hence, it is possible that visitors with disabilities can be more highly sensitive to different elements or situations. Previous studies by $[26,27]$ show that travelers with disabilities evaluate sites according to a different set of criteria, including a number of independent and overlapping factors that are not present for their counterparts without disabilities. Experiences for these kinds of consumers may also be influenced by the opinions of third parties such as caregivers and companions [28]. The result of the experience may be 
satisfactory or unsatisfactory and will affect the customer's behavior, generating memories that will determine their loyalty or degree of recommendation [29]. Another result of the experience is the customer's involvement in future co-creation of experience. [19] show that the consumption experience can be sensory and participative. Customers use their sensory organs in any consumption process, and active participation engages customers in the process of consumer co-creation.

Tourism is a knowledge-intensive sector in which, particularly in the field of culture, the individual's experience is especially emotional and cognitive. Visitor experiences in a museum involve the subjective mental state that participants feel during a service encounter [30] which may include feelings of fun and enjoyment, escape from routine, sharing valuable time with family or friends, and learning [31].

\subsection{Inclusive Management of the Visitor with Disabilities Experience: Relational Spaces}

Experience is important in museums; it has a direct and significant effect on customer satisfaction. The more satisfied the customers, the greater the competitive advantage for the organization, given the effects of satisfaction on customer recommendations and loyalty [32].

Experience is also influenced by psychological factors, however, such as multisensory imagery and emotive aspects. Furthermore [33] argue that the traditional focus on the cognitive and utilitarian dimension does not explain how consumers choose products to satisfy their emotional wants. Hospitality and tourism products such as vacation resorts, museums, leisure, and theme parks are high in both affective and cognitive attributes [34].

Museums are unable to fully control the visitor experience. As a greater obstacle to their inclusive management, this implies they cannot control their customers' perceptions, emotions, and behaviors at all the touchpoints that shape the visitor journey [1]. However, they can try to know their visitors, and design and manage interaction points to influence perceptions, thus increasing interest, involvement, satisfaction, loyalty, and support [35]. Indeed [20-36] all point out the importance of identifying environments that produce different touchpoints and generate customer experience.

The servicescape context is the physical or digital space in which the relationship occurs [37]. It involves physical and environmental dimensions such as design, lighting, smell, sound, and layout. While it impacts on the consumer's five senses, it can also participate or mediate in the individual's internal response to cognitive, emotional, and physiological levels and influence customer behavior, including customer-to-customer behavior [38].

In this respect [39] show how the servicescape influences customer perceptions of service delivery and, importantly, the meaning of the consumption practice for the customer as a combination of the many sensory and contextual elements of a service environment.

Traditionally, museums have focused on the cognitive characteristics of the service environment, such as physical layout and service (exhibitions, lounge facilities, security), in order to offer attractive products and target consumers with effective marketing [31]. (Recently, however, the importance of affective and sensory attributes in the museum experience is increasingly being recognized $[40,41]$. As the hospitality market has overflowed with almost identical cognitive features and interchangeable service elements, companies have achieved competitive differentiation by managing customers' emotional and sensory experiences [42]. Indeed, some companies have now found new ways to emotionally involve their customers by getting them to participate directly, coordinately and continually as co-creators [43].

In fact, recent literature on service consumption [44] and service-dominant logic [45] has shown that co-creation occurs in the customer's own context and reality. It can even be argued that service innovation takes place in a real-time experience [46]. However, the profusion of such consumption contexts requires the management process to include design and control, not only of spaces, but also of the behaviors developed and the relationships established between the agents. Worthy of note in this respect is that inclusive management 
of the experience involves identifying the type of barriers that arise in the spatial, social, and relational contexts, both physical and digital, and understanding how these affect the customer experience. Interestingly [47] show that consumers who fully engage in the positive physical and relational aspects of their consumer experiences are more inclined to develop positive emotions, satisfaction, and loyalty.

\subsection{Barriers to the Memorable Inclusive Experience}

In the context of memorable and satisfactory visitor with disabilities experiences, barriers are defined as all obstacles, whether physical [48] sensory [49], cultural, or social [21,50], that limit or impede people's ability to use products, services, and environments [51].

The academic literature has documented the restrictions experienced by visitors with disabilities, including (1) barriers to accessibility and information, such as lack of access to information, and (2) barriers to integration and social participation, such as discrimination, and even, in the case of invisible disability, fear of not being understood, socially rejected, or simply being unable to cope with the situation [52]. In order to ensure inclusive management, companies need to first identify the more important barriers.

The first basic requirement is to make the physical or built environment accessible to the traveler [53]. In tourism, numerous physical and architectural barriers limit customers' participation in and access to strong positive experiences, to the extent that these barriers become a disincentive to customer activity [54,55]. Another fundamental element in terms of accessibility is quick, easy access to quality information. Interestingly [56] in their study of inclusive heritage experience, found that adapted information made available beforehand enhances the heritage site experience.

Technological development has moved a large part of customer relations online. Any discussion of barriers to information access should therefore consider, not only the information individuals receive in person, but also the information they access online [57]. Some of the barriers to accessibility associated with elements in the natural environment are also found in the digital environment. Consumers' emotions are affected by the service environment. In the context of museums, barriers to integration and participation become apparent when the visitor with disabilities interacts with other people [58] whether museum staff or fellow customers.

Likewise [59] identifies some of the main elements that create barriers to social participation. These include negative attitudes of staff and other customers without disabilities and, in terms of knowledge, lack of information provision and education or training.

These barriers are often due to lack of knowledge and training, or prejudices on the part of the people who come into contact with customers with disabilities [60,61]. Occasionally, however, the reason for the barrier goes beyond the individual level and is due to corporate organizational culture. Social and cultural barriers are a key factor in services such as museums, where relations between visitors and museum staff are essential to the customer experience. Lack of knowledge about visitors with disabilities is one of the main barriers to inclusivity, as it hinders relationship building and leads to reduced or even non-existent quality and other key service delivery elements [62]. Furthermore, lack of diversity awareness is one of the main causes of a negative attitude, not to mention prejudices and discrimination towards PwD among company personnel and even other customers [63].

Furthermore [64] make an important point regarding barriers to inclusion, noting that, besides the direct consequences of barriers in terms of social relations and participation in community activities, the psychological effects on individuals and their immediate environment should also be taken into account. This is a key point in terms of analyzing visitor experience, since the aspirations, objectives, decisions, and abilities of visitors with disabilities will determine their expectations and, therefore, their experience [65]. Indeed, ref. [51] show that, with certain types of disability where dependence on other people is very high, improvements in the emotional levels of visitors with disabilities will also 
have a positive effect on their immediate environment (caregivers, family, groups, and associations).

\section{Materials and Methods}

The study data on which this article draws comes from many research projects under the theme of Culture for All in the city of Barcelona between 2017 and 2019. We selected a highly accessible cultural site in the city of Barcelona to support the visitor with disabilities experience and offer a more inclusive management tool for companies. In 2019, two tours around the CosmoCaixa Barcelona science museum were organized for visitors with disabilities to gain insight into the visitor with disabilities cultural experience. The museum site was previously audited for accessibility by one of the researchers, enabling the researchers to develop, in collaboration with CosmoCaixa, an accessible guide in adapted format for use during the experience (one guide for each tour; see Figure 1). The CosmoCaixa science museum, which belongs to the Fundació La Caixa, opened to the public in 2004 and receives more than a million visitors each year. It has accessible features and offers a host of activities and permanent and temporary exhibitions to provide its visitors with a greater insight into the world of science. The two days of walking tours took place in Barcelona in 2019.

Insert near here: Figure 1 shows examples of adapted communication encounter (accessible guide in Braille format).

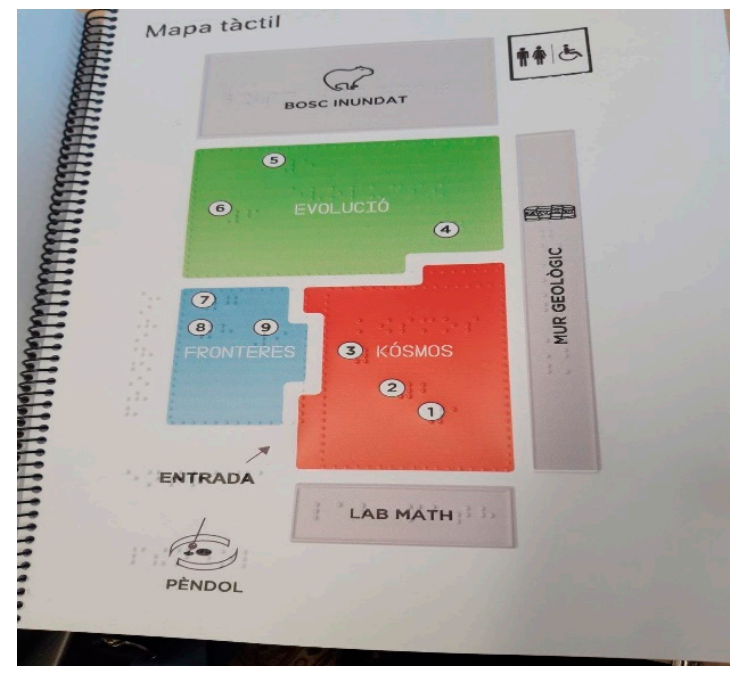

Figure 1. Images of the CosmoCaixa accessible guide in braille format.

The central objective of our project was twofold. Firstly, we aimed to gain insight into how barriers can lead visitors with disabilities to be excluded and how their experience is shaped and perpetuated, using participants' accounts of their museum visit participation experience. This would help to precisely identify the barriers to accessibility and access to information, participation, and social integration that lead to the exclusion of PwD. Our second purpose was to be able to make recommendations to museum managers that will assist in the design of inclusive management tools for implementing positive interventions and making the changes needed to promote social inclusion in the museum context. In line with [66-68] we also encourage allowing visitors with disabilities to explore their own solutions.

To this end, we used qualitative methodology techniques. As discussed by [69] qualitative methods allow researchers to reveal the rich detail of social interactions, describe the emotions involved, and explore what is generally taken for granted through reflection and discussion.

Data was obtained from different sources, including an audit, ethnography, and observation techniques, and interviews after the visit. This mixed data collection allowed 
for a holistic perspective [69]. In addition, data on the emotions experienced throughout the tour were collected using observation techniques, handwritten notes taken during the tour, and semi-structured interviews conducted with sample participants after the tour.

All participants gave their informed consent for inclusion before participating in the study. The approved study protocol number is URL-2nr-2018.

\subsection{Data Collection}

The following data collection techniques were used for the two museum visits, in the following two phases:

1. Data collected during the stay. Thirty-two individuals with disabilities participated in the fieldwork. Researchers collected information using observation techniques, follow-up of participants, handwritten notes, and 40 images.

2. Data collected after the stay. After the stay, data was obtained from individual interviews with participants. Twenty participants with disabilities willing to take part in the post-museum experience were interviewed individually. [70] suggests that between 20 and 30 interviews for grounded theory is an acceptable number. Nine of the participants had intellectual disabilities, six had visual impairment, two had hearing impairment, and three had a physical disability (Table 1).

\subsection{Participants}

Table 1. List of participants in each phase and study.

Table 1. List of participants in each phase and study.

\begin{tabular}{|c|c|c|c|c|c|}
\hline Total Participants & $\begin{array}{l}\text { No. of Participants } \\
\text { with Intellectual } \\
\text { Disability }\end{array}$ & $\begin{array}{l}\text { No. of Participants with } \\
\text { Sensory Disabilities } \\
\text { (Visual) }\end{array}$ & $\begin{array}{c}\text { No. of Participants with } \\
\text { Sensory Disabilities } \\
\text { (Hearing) }\end{array}$ & $\begin{array}{l}\text { No. of Participants } \\
\text { with Physical } \\
\text { Disabilities }\end{array}$ & Total \\
\hline $\begin{array}{l}\text { Data collection Phase 1. Data } \\
\text { collected prior to visit }\end{array}$ & 17 & 10 & 2 & 3 & 32 \\
\hline $\begin{array}{c}\text { Data collection Phase } 2 . \\
\text { Number of participants } \\
\text { (during the visit). Observation } \\
\text { techniques }\end{array}$ & 17 & 10 & 2 & 3 & 32 \\
\hline $\begin{array}{l}\text { Data collection. Interviews in } \\
\text { post-tour survey }\end{array}$ & 9 & 6 & 2 & 3 & 20 out of 32 \\
\hline
\end{tabular}

\subsection{Interviews}

The 30-min interviews proved extremely useful in identifying key disabling barriers related to the participants' visit experience, their perception of the experience in terms of service provision, and the memorability of the experience. The questions used were the same for both tours to ensure consistency [71,72]. Satisfaction was determined by comparing participants' accounts of their actual experiences with their prior expectations of the company and the service [73].

This first section of the final interview includes the participant's profile details. The second section consisted of eight questions on the participant's museum visit experience, while the third section focused on the participant's recommendations for a memorable experience. The interviews were carried out in Spanish between October and December 2019.

The interview questions were exploratory in nature, for example, "Would you recommend the visit to CosmoCaixa to other visitors with disabilities?" If the response was no, the initial question was followed with another, "Can you explain why you would not recommend it?". Here the question was aimed at identifying the main disabling barriers encountered during the museum visit. We also invited participants to explain their own stories by asking open questions, for example, "Can you tell us about a specific negative experience during the museum visit?". In this way, participants with disabilities were encouraged to explain in detail the positive and negative elements of their experience. We 
also explored the participants' impressions of the provision of services and facilities for the current visit.

These questioning strategies were designed to allow the interviewees to play an active role and explain their own narratives. At the same time, service and facilities provision components related to the visitor experience in the museum context were probed from the perception of visitors with disabilities. For example, we considered participants' perceptions of the level of accessibility and universal design, provision of adapted communication, staff and service provision, and materials available (adapted materials in easy-to-read format, braille, tactile maps, 3D materials). This helped us to identify a number of specific barriers within the accessible tourism concepts for managerial recommendations. Inclusive research was considered, with interviews supported by adapted material, in particular for participants with intellectual disabilities or hearing disabilities. Questionnaires in easy-to-read and plain language format with visual features were used where needed for customers with learning difficulties [66] and we had the support of a sign language translator for those with hearing impairment.

\subsection{The Analytical Process}

Finally, a content analysis of the data was conducted. We reviewed all our transcripts, 40 images, and notes several times, and encoded our data [74]. Our aim was to highlight elements that create barriers to people with special access needs in a tourism setting. ATLAS.ti software was used to analyze the study data and create a relational map. The initial step consisted of manually analyzing the data collected to analyze for insights. Next, we identified the main components that formed the barriers. Finally, through coding it was possible to describe the participants' museum experience and the components that contributed to the creation of barriers to memorable experiences that lead visitors with disabilities to be socially excluded. Throughout the selective coding process, the notes, interviews, and coding choices were reviewed several times and compared to literature review concepts [75]. Thus, throughout the selective coding process, the data from the researchers' observations, surveys, and the coding choices were reviewed several times and crosschecked with the literature review concepts.

Theoretical saturation was reached with the twenty participants' accounts [76,77].

Table 2. The coding processes.

Table 2. The coding processes (Figure A1 is an example of accessible displayers and adapted materials).

\begin{tabular}{ccc}
\hline Open Coding & Axial Coding & Main Themes (Selective Coding) \\
\hline See figure above & $\begin{array}{c}\text { Attitude of staff, social interaction with } \\
\text { museum staff. }\end{array}$ & $\begin{array}{c}\text { Hospitality service. Attitude and social interaction with } \\
\text { museum staff as disabling barrier to memorable cultural } \\
\text { experience (participation). }\end{array}$ \\
\hline $\begin{array}{c}\text { Adapted materials and information } \\
\text { provision resources }\end{array}$ & $\begin{array}{c}\text { Lack of information provision resources as a disabling } \\
\text { barrier to memorable cultural experience (participation). }\end{array}$ \\
\hline Accessibility and universal design & $\begin{array}{c}\text { Lack of universal design as a disabling barrier to memorable } \\
\text { cultural experience (accessibility). }\end{array}$ \\
\hline
\end{tabular}

In the next section, we structure our findings according to three types of social practice: (1) being aware of universal design access requirements, (2) accessing information resources, and (3) providing customers with disabilities with good hospitality service. The quotations are included to reflect on the emotions, reactions and experiences of the participants with disabilities who took part in the museum visit.

\section{Results}

In this article, we have explored relationships between visitors with disabilities and tourism staff members in the context of museums in an attempt to improve understanding 
of the phenomenon and provide a more sophisticated starting point for management of hospitality experiences for all.

As a result of our study, we found that, despite the legal framework of the Convention on the Rights of PwD [16], it is not easy for hospitality managers to put this framework into practice and cater to the needs of this segment of the population.

This is due to two main factors:

- First, it is not always easy for hospitality staff to know who counts as disabled. That is, according to [68] disability "identification" is often problematic. The "disabled identity" is far from straightforward.

- Second, hospitality managers need to improve their understanding of the needs of visitors with disabilities. Hospitality managers' lack of awareness stems, in part, from the fact that the social model of disability is quite recent, and that much of society is still unaware of disability, which continues to be stigmatized.

Types of factor influencing the memorable, inclusive visit experience in the context of museums.

Three main categories emerged from the coding process and three types of factor influencing the memorable, inclusive museum visit experience were identified from the data collected: (1) awareness of universal design access requirements, (2) accessing information resources, and (3) providing visitors with disabilities with excellent hospitality.

We have drawn on [7] Alvarez-Sousa and Paniza Prados (2020) methodology of open coding (Figure 2):

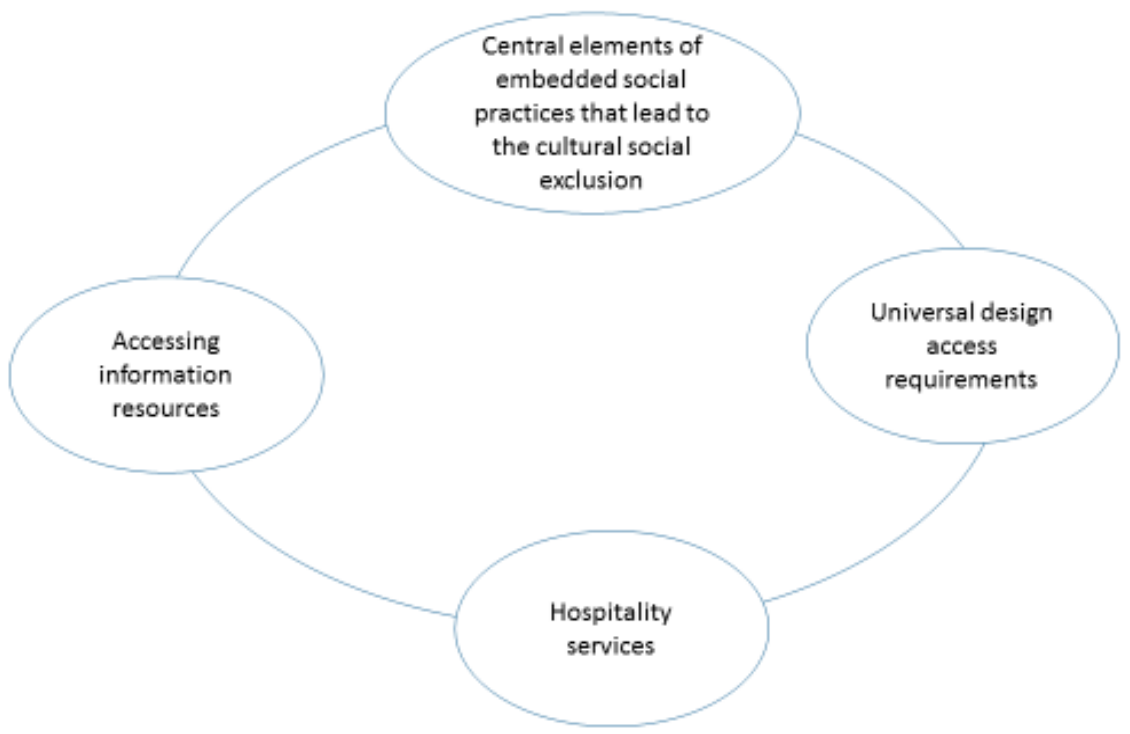

Figure 2. The framework of the central factors influencing the memorable museum experience.

\subsection{Awareness of Universal Design Access Requirements (Accessibility)}

The practices involved in accessing the site are a key example of how the interconnections between different players are vital to the experience of visitors with disabilities, and lead to either inclusion or exclusion for PwD. The case of the visitor with a physical disability who had to wait for service while attempting to access parking reserved for the disabled is a clear example of how some practices can cause visitors with disabilities to feel disadvantaged in comparison to others. This is a disabling barrier that reduces enjoyment for visitors with wheelchairs, who find themselves waiting for service. In such cases, customers with physical disabilities may feel forgotten and invisible to others, and negative emotions may emerge. In parallel, when considering the reasonable adjustments needed by a visitor with disabilities, a person must first be identified as disabled, and this may be a daunting process. One participant explained that she has reservations about identifying her son as disabled in service environments: 
I found the museum setting magnificent, but honestly I expected more service for my companion with an intellectual disability. To access adapted resources like easy-to-read materials, I had to explain to various members of staff that I was accompanied by a disabled person, and make it clear that we were different from other people [...] This detracted from our enjoyment of the visit [...]. (Participant with a child with intellectual disability)

In line with [68] we also found that, regardless of how a visitor with disabilities is identified, in order for a visitor's needs to be effectively met, practices must exist that incorporate and respond to those needs. If a museum has no inclusive strategies and practices in place, the process of identifying visitors with disabilities becomes meaningless:

There was just one parking space reserved for people with disabilities at the museum, and I was told to go right in and park at the entrance [...] As I approached the site, there was a poorly-placed intercom outside which seemed not to be working properly; as a result I had to wait a while for the service [...]. (Participant with physical disability)

Because there were so many members taking part in the group, site staff didn't realize I couldn't follow the path with a manual wheelchair, so I found going up Creu Coberta Street in Sants extremely tiring [ ... ]. (Participant with physical disability)

\subsection{Accessing Information Resources (Participation)}

Communication encounters are of vital importance to visitors with disabilities. By means of communication resources provided by the company (online information, written information, signposting, etc.), visitors with disabilities are able to make decisions about how the activity fits in with their interests and their needs. Currently, the lack of communication in adapted formats (visual, tactile, electronic, braille, etc.) is a serious disabling barrier for this group. We found that participants lacked the adapted information they needed for their cultural experience to be a good experience. The one participant who needed a tactile map, or even the participant who found the online information insufficient to be able to make a suitability appraisal, are clear examples of barriers to memorable tourism experiences.

I love museums, but I find it difficult to go on my own, since there is little chance of finding a sign language interpreter on a spur-of-the-moment basis [...] You need to make a group reservation a long time in advance. (Participant with hearing impairment)

Communications encounters have been found to be of vital importance in freeing visitors with disabilities from disabling social barriers, in two respects: first, to be able to make decisions about how they can fit into the activity; and second, to be able to obtain service from museum staff that meets their communication needs without having to wait. Our study participants expressed concerns about receiving information provision in adapted formats that met their communication needs. Customers wanted clear and understandable information and our participants reported that, at times, this was not forthcoming.

According to [78] a major disabling social practice which leads to the exclusion of participants with disabilities is the absence of proper resources or mediators, typically provided by companies, in order that participants can be autonomous. Where adequate resources are not provided, exclusion occurs, since participants with disabilities will not be able to follow the tour in equal conditions to their counterparts without disabilities. For instance, it is easier for a person with visual impairment to understand and follow a museum visit when tactile maps and text in alternative formats are available to them. In the same way, it is important for a person with an intellectual disability to have access to easy-to-read and visual formats to enable them to understand what is going on throughout the tour.

I was told about the museum activity by a colleague from my NGO, and I was immediately interested in taking part [...] I immediately tried to get additional information on the map and the route from the Internet, and by sending emails. However, there was no 
adapted information, only information in text format, and I had to explain my needs several times to staff to get the right information [... ] I think it should be easier to access the website and get the right information in an adapted format [...]. (Participant with visual impairment)

On occasions, as a result of undesirable practices, visitors with disabilities were made to feel they were the cause of the confusion:

I expected the visit to be straightforward, since it was supposed to be a visit for all. But because I have limited access with my wheelchair, sometimes I found myself waiting a while for an alternative access route, so obviously it was difficult for me to follow the visitor group [...]. (Participant with physical impairment)

\subsection{Providing Visitors with Disabilities with Good Hospitality Service (Participation)}

Another disabling barrier may be present in the context of the museum staff-visitor relationship. Service encounters are key to understanding barriers. It is quite common for tourism providers to lack awareness of the needs of visitors with disabilities. In our context, the personal mediator ([78] or tour guide is a key element for inclusion. A clear example is provided by the participant who found the cultural experience very poor, since the tour guide seemed not to understand his communication needs, causing him to feel like a misfit in the activity. In line with [73] satisfaction is determined by people's comparison of their actual experiences with their expectations of the company and the service [73]. Therefore, the appearance of all these previously mentioned disabling barriers will clearly lead to dissatisfaction in visitors with disabilities, when their access and communication needs are not taken into consideration in a normalized way.

The tour guide was nice to us, but began the activity route speaking very quietly and quickly, so it was very difficult for us to follow the activity [...]. (Participant with intellectual disability)

Such negative museum experiences led participants with disabilities to feel isolation and helplessness. For example, another participant explained:

At the end of the visit, participants were given a souvenir gift but, because I have visual impairment, I was told that for the time being there were none available in tactile format. I felt that I had been treated differently from others because of my physical condition [...]. (Participant with intellectual disability)

\section{Discussion}

CosmoCaixa is known for its endeavors in accessibility and inclusiveness. Our study aimed to identify an inclusive management tool with a greater presence in the visitor with disabilities' own context and reality. We have seen situations when participants did identify a few elements of service encounters that caused them distress, loss of enjoyment, and bodily discomfort. In our research project, we have explored many similar encounters, in which the experience is strongly influenced by the interaction between museum staff and visitors with disabilities. In view of these results, we submit that far more is required than simply providing visitors with disabilities with the appropriate materials and resources to allow them to take part in the cultural activity.

Indeed, we have seen how certain encounters or touchpoints may lead to social exclusion by causing visitors with disabilities to feel that they are the problem when obtaining materials, resources, or adaptations. Nevertheless, since encounters can be redesigned and reshaped to be more inclusive, our results may help museum managers to find ways to change the aspects of service provision that dictate how visitors with disabilities take part in those practices.

Specifically, in the inclusive management context we found that, even in the case of a museum with a high degree of accessibility and inclusiveness, museum management needs to be aware of specific factors that are memorable to the visitor with disabilities: allocation of proper resources; importance of staff communication, service encounters, and 
relevance of information provision as a support tool for participants with communication and learning difficulties; and application of universal design before the visit takes place [56]. More importantly, in their encounters with museum staff, visitors with disabilities felt that having to explain their disabilities and wait for service resulted in exclusionary situations, where they were unintentionally treated differently from other customers without disabilities because of their condition. When this happens, visitors with disabilities feel forgotten and unequally treated in spite of the current laws and regulations.

The model can also be used by museum managers to redesign touchpoints and interactions to meet the wants and needs of visitors with disabilities. In our study, we have first explored how each stage of the museum experience journey can throw up encounters or touchpoints which can be disabling. Problems emerge when encounters are designed without consideration for the needs of visitors with disabilities; this results in their different access needs becoming clearly visible to others, leaving the visitors with disabilities feeling anxiety and helplessness.

We suggest that any tourism setting must have an accessible plan, with a standard way of doing things, which shapes how museum staff and visitors interact with the service as well as people's experiences as visitors. This study has sought to improve understanding of the visitor with disabilities experience in an effort to find patterns of disabling barriers and make museum settings more accessible for all.

Museum managers could be aware of the most relevant elements in the shaping of inclusive experiences for visitors with disabilities: lack of adapted information provision (communication encounter), the importance of universal design (usage encounter), and the importance of providing visitors with disabilities with a hospitality service (service encounter). These issues are important considerations that provide a more inclusive understanding of disability and the nature of inclusive museums than has been identified in the literature to date.

It is in the best business interests of museums to improve the alignment of their practices and services to visitors with disabilities.

Author Contributions: Conceptualization M.C.C.; methodology M.C.C.; software M.C.C..; validation, M.C.C. formal analysis, M.C.C. investigation, M.C.C..; resources, M.C.C.; data curation, M.C.C. writing-M.C.C. and A.I.J.Z. writing-M.C.C. and A.I.J.-Z., visualization, M.C.C.; supervision M.C.C.; project administration, M.C.C.; funding acquisition, M.C.C. All authors have read and agreed to the published version of the manuscript.

Funding: This research received the external finding of Foundation "La Caixa".

Institutional Review Board Statement: This project is part of a boader project called Culture for all. I have added the following sentence: The study was conducted according to the guidelines of the Declaration of Helsinki, and approved by the Institutional Review Board of University Ramon Llull (protocol code URL-2nr-2018 approved o 8th December 2018).

Informed Consent Statement: Informed consent was obtained from all subjects involved in the study.

Data Availability Statement: Data is partially contained within the article. While we have included in the article a number of photos that do not include pictures of the respondents to avoid them to be identified as a vulnerable group they are.

Conflicts of Interest: The authors declare no conflict of interest. 


\section{Appendix A}

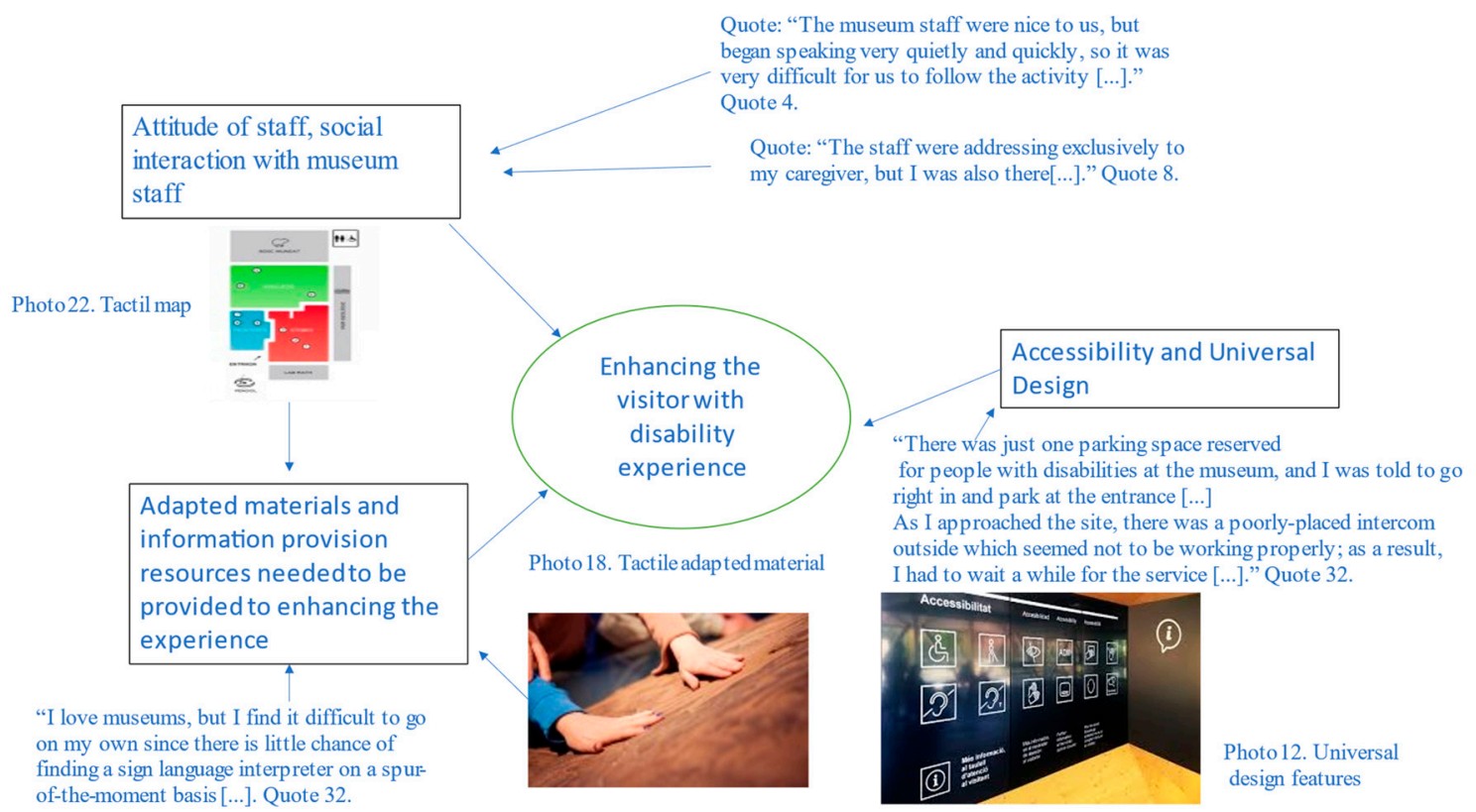

Figure A1. An example of accessible displayers and adapted materials.

\section{References}

1. Ruiz-Alba, J.L.; Nazarian, A.; Rodríguez-Molina, M.A.; Andreu, L. Museum visitors' heterogeneity and experience processing. Int. J. Hosp. Manag. 2019, 78, 131-141. [CrossRef]

2. Prebensen, N.K.; Xie, J. Efficacy of co-creation and mastering on perceived value and satisfaction in tourists' consumption. Tour. Manag. 2019, 60, 166-176. [CrossRef]

3. Piqueras-Fiszman, B.; Jaeger, S.R. The incidental influence of memories of past eating occasions on consumers' emotional responses to food and food-related behaviors. Front. Psychol. 2016, 7, 943. [CrossRef] [PubMed]

4. Butcher-Younghans, S. Historic House Museums: A Practical Handbook for Their Care, Preservation, and Management; Oxford University Press: Oxford, UK, 1993.

5. Conti, E.; Forlani, F.; Pencarelli, T. The visiting experience of a cultural city in the experiential perspective: The case of Urbino. Il capitale culturale. Stud. Value Cult. Herit. 2020, 21, 391-424.

6. Brown, K.; Mairesse, F. The definition of the museum through its social role. Curator Mus. J. 2018, 61, 525-539. [CrossRef]

7. Kinsley, R.P. Inclusion in museums: A matter of social justice. Mus. Manag. Curatorship 2016, 31, 474-490. [CrossRef]

8. Stone, M.D.; Woodcock, N.D. Interactive, direct and digital marketing. J. Res. Interact. Mark. 2014, 8, 4-17. [CrossRef]

9. Del Chiappa, G.; Andreu, L.; Gallarza, M.G. Emotions and visitors' satisfaction at a museum. Int. J. Cult. Tour. Hosp. Res. 2014, 8 , 420-431. [CrossRef]

10. Urquhart, I. The psychology of inclusion: The emotional dimension. In Psychology for Inclusive Education; Routledge: Abingdon, UK, 2008; Chapter 6; pp. 78-90.

11. Meacham, H.; Cavanagh, J.; Bartram, T.; Laing, J. Ethical management in the hotel sector: Creating an authentic work experience for workers with intellectual disabilities. J. Bus. Ethics 2019, 155, 823-835. [CrossRef]

12. Kastenholz, E.; Eusébio, C.; Figueiredo, E. Contributions of tourism to social inclusion of persons with disability. Disabil. Soc. 2015, 30, 1259-1281. [CrossRef]

13. Rimmerman, A.; Gur, A.; Muraver, M.; Yurkevich, O. Personal and social life of Israeli aging mothers to adult children with intellectual disabilities: Differences related to family status and living arrangement. Int. J. Deve. Disabil. 2019, 64, 81-85. [CrossRef]

14. Taylor, W.D.; Cobigo, V.; Ouellette-Kuntz, H.A. family systems perspective on supporting self-determination in young adults with intellectual and developmental disabilities. J. Appl. Res. Intellect. Disabil. 2019, 32, 1116-1128. [CrossRef] [PubMed]

15. Poria, Y.; Ashworth, G. Heritage tourism-Current resource for conflict. Ann. Tour. Res. 2009, 36, 522-525. [CrossRef]

16. United Nations Committee on the Rights of Persons with Disabilities. Inquiry Concerning the United Kingdom of Great Britain and Northern Ireland Carried out by the Committee under Article 6 of the Optional Protocol to the Convention. 2016. Available online: CRPD/C/15/R.2/Rev.1.http:/ / www.ohchr.org/EN/HRBodies/CRPD/Pages/InquiryProcedure.aspx (accessed on 24 December 2020).

17. Chuang, S.H. Co-creating social media agility to build strong customer-firm relationships. Ind. Mark. Manag. 2020, 84, $202-211$. [CrossRef] 
18. Prentice, C.; Wang, X.; Loureiro, S.M.C. The influence of brand experience and service quality on customer engagement. J. Retail. Consum. Serv. 2016, 50, 50-59. [CrossRef]

19. Adhikari, A.; Bhattacharya, S. Appraisal of literature on customer experience in tourism sector: Review and framework. Curr. Issues Tour. 2016, 19, 296-321. [CrossRef]

20. Lemon, K.N.; Verhoef, P.C. Understanding customer experience throughout the customer journey. J. Mark. 2016, 80, 69-96. [CrossRef]

21. Sterchele, D. Memorable tourism experiences and their consequences: An interaction ritual (IR) theory approach. Ann. Tour. Res. 2020, 81, 102847. [CrossRef]

22. Farah, M.F.; Ramadan, Z.B.; Harb, D.H. The examination of virtual reality at the intersection of consumer experience, shopping journey and physical retailing. J. Retail. Consum. Serv. 2019, 48, 136-143. [CrossRef]

23. De Farias, S.A.; Aguiar, E.C.; Melo, F.V.S. Store atmospherics and experiential marketing: A conceptual framework and research propositions for an extraordinary customer experience. Int. Bus. Res. 2014, 7, 87. [CrossRef]

24. Hamilton, R.; Price, L.L. Consumer journeys: Developing consumer-based strategy. J. Acad. Mark. Sci. 2019, 47, 87-191. [CrossRef]

25. Trabelsi-Zoghlami, A.; Touzani, M. How real are virtual experiences?: For a better understanding of virtual experiences and their impact on consumers' real life. Eur. J. Mark. 2019, 53, 1612-1636. [CrossRef]

26. Darcy, S.; Pegg, S. Towards strategic intent: Perceptions of disability service provision amongst hotel accommodation managers. Int. J. Hosp. Manag. 2011, 30, 468-476. [CrossRef]

27. Pfeiffer, B.; Sell, A.; Bevans, K.B. Initial evaluation of a public transportation training program for individuals with intellectual and developmental disabilities. J. Transp. Health 2020, 16, 100813. [CrossRef]

28. Tao, B.C.; Goh, E.; Huang, S.; Moyle, B. Travel constraint perceptions of people with mobility disability: A study of Sichuan earthquake survivors. Tour. Recreat. Res. 2019, 44, 203-216. [CrossRef]

29. Harrison-Walker, L.J. The effect of consumer emotions on outcome behaviors following service failure. J. Serv. Mark. 2019, 33, 285-302. [CrossRef]

30. De Angeli, D.; Kelly, R.M.; O’Neill, E. Beyond Happy-or-Not: Using Emoji to Capture Visitors' Emotional Experience. Curator Mus. J. 2020, 63, 167-191. [CrossRef]

31. Su, Y.; Teng, W. Contemplating museums' service failure: Extracting the service quality dimensions of museums from negative on-line reviews. Tour. Manag. 2018, 69, 214-222. [CrossRef]

32. Sharma, P.; Jain, K.; Kingshott, R.P.; Ueno, A. Customer engagement and relationships in multi-actor service ecosystems. J. Bus. Res. 2020, in press. [CrossRef]

33. Kim, D.; Perdue, R.R. The effects of cognitive, affective, and sensory attributes on hotel choice. Int. J. Hosp. Manag. 2013, 35, 246-257. [CrossRef]

34. Ahn, J.; Lee, C.K.; Back, K.J.; Schmitt, A. Brand experiential value for creating integrated resort customers' co-creation behaviour. Int. J. Hosp. Manag. 2019, 81, 104-112. [CrossRef]

35. Kranzbühler, A.M.; Kleijnen, M.H.; Morgan, R.E.; Teerling, M. The multilevel nature of customer experience research: An integrative review and research agenda. Int. J. Manag. Rev. 2018, 20, 433-456. [CrossRef]

36. Kranzbühler, A.M.; Kleijnen, M.H.; Verlegh, P.W. Outsourcing the pain, keeping the pleasure: Effects of outsourced touchpoints in the customer journey. J. Acad. Mark. Sci. 2019, 47, 308-327. [CrossRef]

37. Helmefalk, M.; Marcusson, L. Gamification in a servicescape context: A conceptual framework. Int. J. Internet Mark. Advert. 2019, 13, 22-46. [CrossRef]

38. Roy, S.K.; Singh, G.; Hope, M.; Nguyen, B.; Harrigan, P. The rise of smart consumers: Role of smart servicescape and smart consumer experience co-creation. J. Mark. Manag. 2019, 35, 1480-1513. [CrossRef]

39. Lockwood, A.; Pyun, K. How do customers respond to the hotel servicescape? Int. J. Hosp. Manag. 2019, 82, 231-241. [CrossRef]

40. Antón, C.; Camarero, C.; Garrido, M.J. A journey through the museum: Visit factors that prevent or further visitor satiation. Ann. Tour. Res. 2018, 73, 48-61. [CrossRef]

41. Lee, H.; Jung, T.H.; tom Dieck, M.C.; Chung, N. Experiencing immersive virtual reality in museums. Inf. Manag. 2020, 57, 103229. [CrossRef]

42. Keiningham, T.; Aksoy, L.; Bruce, H.L.; Cadet, F.; Clennell, N.; Hodgkinson, I.R.; Kearney, T. Customer experience driven business model innovation. J. Bus. Res. 2020, 116, 431-440. [CrossRef]

43. Kim, E.G. Co-Created Destination Branding for Creative MICE Tourism: Building Synergies with Cultural Heritage Assets. Ph.D. Thesis, Arizona State University, Tempe, AZ, USA, 2019.

44. Vargo, S.L.; Lusch, R.F.; Akaka, M.A.; He, Y. Service-dominant logic. In The Routledge Handbook of Service Research Insights and Ideas; Routledge: Abingdon, UK, 2020; p. 3.

45. Grönroos, C.; Voima, P. Critical service logic: Making sense of value creation and co-creation. J. Acad. Mark. Sci. 2013, 41, 133-150. [CrossRef]

46. Buhalis, D.; Sinarta, Y. Real-time co-creation and nowness service: Lessons from tourism and hospitality. J. Travel Tour. Mark. 2019, 36, 563-582. [CrossRef]

47. Rychalski, A.; Hudson, S. Asymmetric effects of customer emotions on satisfaction and loyalty in a utilitarian service context. J. Bus. Res. 2017, 71, 84-91. [CrossRef] 
48. Schüler, M.; Fee Maier, M.; Liljedal, K.T. Motives and barriers affecting consumers' co-creation in the physical store. Int. Rev. Retail Distrib. Consum. Res. 2020, 30, 289-310. [CrossRef]

49. Papadimitriou, N.; Plati, M.; Markou, E.; Catapoti, D. Identifying accessibility barriers in heritage museums: Conceptual challenges in a period of change. Mus. Int. 2016, 68, 33-47. [CrossRef]

50. De Bellis, E.; Johar, G.V. Autonomous Shopping Systems: Identifying and Overcoming Barriers to Consumer Adoption. J. Retail. 2020, 9, 74-87. [CrossRef]

51. McKercher, B.; Darcy, S. Re-conceptualizing barriers to travel by people with disabilities. Tour. Manag. Perspect. 2018, 26, 59-66. [CrossRef]

52. Devile, E.; Kastenholz, E. Accessible tourism experiences: The voice of people with visual disabilities. J. Policy Res. Tour. Leis. Events 2018, 10, 265-285. [CrossRef]

53. Tomej, K. Accessible and equitable tourism services for travelers with disabilities: From a charitable to a commercial footing. In Corporate Sustainability and Responsibility in Tourism; Springer: Cham, Switzerland, 2019; pp. 65-78.

54. Badia, M.; Orgaz, B.M.; Verdugo, M.A.; Ullán, A.M.; Martínez, M.M. Personal factors and perceived barriers to participation in leisure activities for young and adults with developmental disabilities. Res. Dev. Disabil. 2011, 32, 2055-2063. [CrossRef]

55. Schmitt, L.; Delbosc, A.; Currie, G. Learning to use transit services: Adapting to unfamiliar transit travel. Transportation 2018, 46, 1-17. [CrossRef]

56. Cerdan Chiscano, M.; Binkhorst, E. Heritage sites experience design with special needs customers. Int. J. Contem. Hosp. Manag. 2019, 31, 4211-4226. [CrossRef]

57. Zimmermann, M.; Jucks, R. How experts' use of medical technical jargon in different types of online health forums affects perceived information credibility: Randomized experiment with laypersons. J. Med. Internet Res. 2018, 20, 30. [CrossRef] [PubMed]

58. Lehto, X.; Luo, W.; Miao, L.; Ghiselli, R.F. Shared tourism experience of individuals with disabilities and their caregivers. J. Destin. Mark. Manag. 2018, 8, 185-193. [CrossRef]

59. Adam, I. Accommodators or non-accommodators? A typology of hotel frontline employees' attitude towards guests with disabilities. Int. J. Hosp. Manag. 2019, 82, 22-31. [CrossRef]

60. Needham-Beck, S.C.; Aujla, I.J. Development of a performance evaluation tool to track progress in an inclusive dance syllabus. Res. Dance Educ. 2020, 1-9. [CrossRef]

61. Sarker, D. Discrimination against people with disabilities in accessing microfinance. Alter 2020, 14, 318-328. [CrossRef]

62. Chikuta, O.; du Plessis, L.; Saayman, M. Nature-based travel motivations for people with disabilities. Afr. J. Hosp. Tour. Leis. 2017, 6,16 .

63. Dover, T.L.; Kaiser, C.R.; Major, B. Mixed signals: The unintended effects of diversity initiatives. Soc. Issues Policy Rev. 2020, 14, 152-181. [CrossRef]

64. Kagan, M.; Itzick, M. The Effect of Gender and Stigma on the Self-Reported Likelihood of Seeking Social Workers' Help by Social Workers versus Non Social Workers. Br. J. Soc. Work 2020, 50, 389-404. [CrossRef]

65. Andrich, D. An expanded derivation of the threshold structure of the polytomous Rasch model that dispels any "threshold disorder controversy". Educ. Psychol. Meas. 2013, 73, 78-124. [CrossRef]

66. Gillovic, B.; McIntosh, A.; Cockburn-Wootten, C.; Darcy, S. Having a voice in inclusive tourism research. Ann. Tour. Res. 2018, 71, 54-56. [CrossRef]

67. Walmsley, J.; Johnson, K. Inclusive Research with People with Learning Disabilities: Past, Present, and Futures; Jessica Kingsley Publishers: London, UK, 2020.

68. Williams, V.; Tarleton, B.; Heslop, P.; Porter, S.; Sass, B.; Blue, S.; Mason-Angelow, V. Understanding disabling barriers: A fruitful partnership between Disability Studies and social practices? Disabil. Soc. 2018, 33, 157-174. [CrossRef]

69. Lamers, M.; Van der Duim, R.; Spaargaren, G. The relevance of practice theories for tourism research. Ann. Tour. Res. 2017, 62, 54-63. [CrossRef]

70. Cresswell, J.W. Qualitative Inquiry and Research Design: Choosing Among Five Traditions, 2nd ed.; Sage: Thousand Oaks, CA, USA, 1998.

71. Josselson, R. Interviewing for Qualitative Inquiry: A Relational Approach; Guilford Press: New York, NY, USA, 2013.

72. Spradley, J. Asking descriptive questions. Ethnogr. Interview 1979, 1, 44-61.

73. Oliver, R.L. Cognitive, affective, and attribute bases of the satisfaction response. J. Consum. Res. 1993, 20, 418-430. [CrossRef]

74. Saldaña, J. The Coding Manual for Qualitative Researchers, 3rd ed.; Sage: London, UK, 2015.

75. Rowley, J. Conducting research interviews. Manag. Res. Rev. 2012, 35, 260-271. [CrossRef]

76. Mason, M. Sample Size and Saturation in PhD Studies Using Qualitative Interviews [63 paragraphs]. Forum Qualitative Sozialforschung/Forum Qual. Soc. Res. 2010, 11. art.8. [CrossRef]

77. Marshall, M.N. Sampling for qualitative research. Fam. Pract. 1996, 13, 522-526. [CrossRef] [PubMed]

78. Tussyadiah, I.P. Toward a Theoretical Foundation for Experience Design in Tourism. J. Travel Res. 2014, 53, 543-564. [CrossRef] 